\title{
Patient profiling in diabetes and role of canagliflozin
}

This article was published in the following Dove Press journal:

Pharmacogenomics and Personalized Medicine

I8 November 2014

Number of times this article has been viewed

\author{
Ambika Amblee ${ }^{1,2}$ \\ 'Division of Endocrinology, John $\mathrm{H}$ \\ Stroger Jr Hospital of Cook County, \\ ${ }^{2}$ Rush University Medical Center, \\ Chicago, IL, USA
}

Background: Physicians attempt to achieve glycemic goals in patients with type 2 diabetes mellitus (T2DM) through various means, including glucose-lowering medications. There is interindividual variability in response to medications, which can be partially explained by the presence of genetic polymorphisms that affect drug metabolism. Pharmacogenomics studies the hereditary basis of interpatient variations in drug response and aims to identify subgroups of patients whose drug management could be tailored accordingly. The aim of this review is to explore patient profiling in the management of T2DM with a focus on the sodium glucose transporter inhibitor canagliflozin.

Methods: The PubMed database was searched using the terms "pharmacogenomics" and "diabetes" through May 31, 2014. Published articles and abstracts presented at national/ international meetings were considered.

Results and conclusion: Genome-wide association studies have opened the door for patient profiling and research into genetic variants in multifactorial T2DM. Clinically, it may be possible to tailor the type of medication used based on the presence or absence of the various genetic variants. However, the polymorphisms studied may only explain some of the variability in response to T2DM drugs and needs further validation to ensure its authenticity. There are still unidentified factors which appear to play a role in the interindividual variability seen in clinical practice. The potential exists for pharmacogenomics to promote efficacious, safe, and cost-effective individualized diabetes management. Pharmacogenomics is still in its early stages, and the idea of defining patients genetically to predict individual responses to drugs and obtain safe and effective T2DM management is promising, in spite of existing barriers. Currently, clinical profiling of patients with T2DM and using an individualized approach with most drugs, including canagliflozin, based on comorbid conditions still remains the most accepted approach for the management of T2DM.

Keywords: personalized medicine, pharmacogenomics, genetic variants

\section{Introduction}

The primary goal of type 2 diabetes mellitus (T2DM) management is to prevent longterm complication. Even with various means, including glucose-lowering medications, there are still barriers to achieving and maintaining glycemic goals. ${ }^{1}$ In the 2012 position statement, the American Diabetes Association emphasized that individualizing the management with consideration to different clinical factors is important. ${ }^{2}$ However, it is difficult for the guidelines to take into account individual variation in responses to pharmacological and lifestyle interventions. Physicians attempt to achieve glycemic goals through an algorithmic approach based on the patient's responses to various antihyperglycemic agents. The wide interpatient variability seen in clinical
Correspondence: Ambika Amblee Division of Endocrinology, John $\mathrm{H}$ Stroger Jr Hospital of Cook County, 1900 West Polk Street, Suite 805, Chicago, IL 606I2, USA

Tel +I 3/28640543

Fax +I 3128649734

Email aamblee@cookcountyhhs.org
Pharmacogenomics and Personalized Medicine 2014:7 367-377 
practice can be partially explained by the presence of genetic polymorphisms which affect the absorption, distribution, metabolism, and excretion of drugs.

Pharmacogenomics studies the hereditary basis of interpatient variations in drug response and aims to identify subgroups of patients whose drug management could be tailored accordingly. This can be an important step in true individualization of therapy, which is lacking at present. The aim of this review is to explore patient profiling in the management of T2DM with a focus on the sodium glucose transporter inhibitor canagliflozin.

\section{Genetic variants associated with response to oral antihyperglycemic agents metformin}

The American Diabetes Association recommends metformin as the first line drug to be used in patients with T2DM. ${ }^{3}$ Response to metformin can vary significantly at the individual level and cannot be predicted by any features found clinically. ${ }^{4}$ In fact, in 2,064 T2DM patients, the glycemic response to metformin was similar in nonobese and obese patients. ${ }^{4}$ Metformin is hydrophilic and needs active transportation into the tissues. ${ }^{5}$ The main transporters are the PMAT encoded by the gene SLC29A4, OCT1 encoded by gene $S L C 22 A 1$, OCT 2 encoded by gene $S L C 22 A 2$ and OCT 3 encoded by gene $S L C 22 A 3 .^{6-8}$ In the renal cell, there are two other transporters called MATE1 and MATE2 encoded by genes $S L C 47 A 1$ and $S L C 47 A 2$, respectively. ${ }^{8}$

In a retrospective study in 24 responders and nine nonresponders of metformin in T2DM patients, the single nucleotide polymorphisms (SNPs) of $S L C 22 A 1,-43 \mathrm{~T}>\mathrm{G}$ in intron 1, was a negative predictor of metformin response while the variant 408 Met $>$ Val $(1222 \mathrm{~A}>\mathrm{G})$ in exon 7 was a positive predictor, with a predictive accuracy of 55.5\% $(P<0.05) .{ }^{9}$ In the Rotterdam study, with $102 \mathrm{~T} 2 \mathrm{DM}$ patients, where associations between eleven SNPs in the SLC22A1 gene and change in the $\mathrm{A}_{1 \mathrm{c}}$ were analyzed, the SNP rs622342 was associated with the glucose-lowering effect of metformin. ${ }^{7}$ For each minor $\mathrm{C}$ allele at rs622342, the $\mathrm{A}_{1 \mathrm{c}}$ levels were reduced by $0.28 \%$ (95\% confidence interval [CI] $0.09-0.47, P=0.005){ }^{7}$

A genome-wide association study on glycemic response to metformin in 1,024 Scottish patients with T2DM was done, and replication was attempted in two cohorts of 1,783 Scottish patients and 1,113 patients from the United Kingdom Prospective Diabetes Study (UKPDS). ${ }^{10}$

In 1,024 Scottish observational genetic cohort on metformin therapy, the minor $\mathrm{C}$ allele of the most strongly associated SNP, rs 11212617, had a frequency of $44 \%$ and was associated with treatment success $\left(\mathrm{A}_{1 \mathrm{c}}<7 \%\right)$, with an allelic odds ratio (OR) of 1.64 (95\% CI 1.37-1.99, $\left.P=1.9 \times 10^{-7}\right)$, and it was associated with lower treatment $\mathrm{A}_{1 \mathrm{c}}$ (per allele $\beta-0.18 \%$ [95\% CI -0.26 to -0.1$\left.], P=1.8 \times 10^{-5}\right)$. In the two replication cohorts, the minor $\mathrm{C}$ allele of rs 11212617 was associated with treatment success: allelic OR 1.21, 95\% CI 1.05-1.38, $P=0.007$ and allelic OR $1.37,95 \%$ CI 1.1-1.72, $P=0.006$, respectively.

The meta-analysis of all 3,920 patients identified a SNP, rs11212617 of the ATM gene, known to be involved in DNA repair and cell cycle control, which was associated with treatment success (OR $-1.35,95 \%$ CI 1.22-1.49, $P=2.9 \times 10^{-9}$ ), and each copy of the minor $\mathrm{C}$ allele of rs11212617 was associated with $0.11 \%\left(P=6.6 \times 10^{-7}\right)$ lower absolute treatment $\mathrm{A}_{1 \mathrm{c}}{ }^{10}$

Further meta-analysis of 2,264 patients on metformin monotherapy showed that the OR for treatment success was $1.42\left(95 \%\right.$ CI $\left.1.26-1.62, P=4 \times 10^{-8}\right) .{ }^{10}$ In a subgroup analysis of 284 patients on metformin from the UKPDS study, $19 \%$ of patients who had two copies of the $\mathrm{C}$ allele at rs 11212617 had a 3.3-fold greater likelihood of achieving an $\mathrm{A}_{1 \mathrm{c}}<7 \%$, which increased the variance in the response to metformin by $2.5 \%$ from $27.5 \%$ to $30 \%(P=0.007) .{ }^{10}$

In the South Danish Diabetes Study, 27 SNPs and one deletion of the metformin transporter genes were tested in 371 T2DM patients. ${ }^{11}$ The mean trough steady-state plasma concentration of metformin was $576 \mathrm{ng} / \mathrm{mL}$, with a wide, 80 -fold range $(54-4,133 \mathrm{ng} / \mathrm{mL})$, indicating that it was a true interindividual variability. Patients heterozygous for the minor alleles rs72552763, rs12208357, rs34130495, and rs34059508 in SLC22A1 showed a significantly lower trough concentration of metformin, which was additive with increasing number of reduced function SNPs. ${ }^{11} \mathrm{~A}$ large difference in the levels of OCT1/ OCT3 genetic variants expression in the liver, kidney, and intestines may contribute to reduced intestinal absorption, variations in hepatic uptake, increased renal clearance, and reduced clinical effect of metformin. ${ }^{11}$ The variant rs3413095 in SLC22A1 was associated with a $1.1 \%(95 \%$ CI $0.4-1.8, P=0.003)$ higher $\mathrm{A}_{1 \mathrm{c}}$ compared to patients who were homozygous for the wild-type allele at 6 months. The presence of SNP rs34399035 of SLC47A2 in the heterozygous patients was thought to be associated with a long-term decrease in $\mathrm{A}_{1 \mathrm{c}}$ $1.1 \%(95 \% \mathrm{CI}-0.1-2.2, P=0.06)$ compared with the wildtype patients over 24 months. ${ }^{11}$

In 52 men with heart disease and metabolic syndrome or T2DM who were compared to 46 healthy controls, metformin 
exhibited a high therapeutic efficacy in patients who carried the Pro/Pro allele of the SNP Pro12Ala polymorphism of the PPAR $\gamma 2$ gene. ${ }^{12}$ These patients had significant reduction in weight, waist circumference, body mass index (BMI), and concentrations of total cholesterol and inflammatory factors like interleukin (IL)-1beta, IL-6, IL-8, and tumor necrosis factor-alpha. ${ }^{12}$

\section{Sulphonylureas and meglitinides}

Sulphonylureas (SU), one of the oldest oral agents used in T2DM, stimulates insulin secretion by inhibiting adenosine triphosphate (ATP)-sensitive potassium (KATP) channels. ${ }^{3}$ Meglitinides act similarly but produce a less sustained rise in insulin secretion. SU have been well studied as they have implication in the treatment of monogenic diabetes. ${ }^{13}$ Gene mutations in the inwardly rectifying potassium channel (KCNJ11) and the $A B C C 8$ modify the insulin response to SU therapy and may be responsible for the interindividual variability and adverse effects seen in T2DM patients. ${ }^{13}$

SU given to 101 T2DM patients uncontrolled on metformin monotherapy showed a higher decrease in $\mathrm{A}_{1 \mathrm{c}}$ at 6 months in $\mathrm{K}$ allele carriers of the $K C N J 11$ gene variant E23K when compared with EE homozygotes (1.04\% $\pm 0.10 \%$ versus $0.79 \% \pm 0.12 \%, P=0.036$, respectively). ${ }^{14} \mathrm{~K}$ allele carriers of the $\mathrm{E} 23 \mathrm{~K}$ variant of the KCNJ11 gene ${ }^{15}$ and the Gly972Arg polymorphism of the insulin receptor substrate $1(I R S 1)^{16}$ were more susceptible to secondary failure, defined as requiring insulin secondary to plasma glucose levels $>300 \mathrm{mg} / \mathrm{dL}$. In $525 \mathrm{~T} 2 \mathrm{DM}$ patients, the frequency of carriers of the K allele of the SNP E23K of the KCNJ11 gene (E23K heterozygotes and $\mathrm{K} 23 \mathrm{~K}$ homozygotes) was higher $(66.8 \%)$ in patients who failed SU therapy compared to $58 \%$ in patients who did not fail, and they had a significant relative risk of secondary failure of 1.45 (95\% CI 1.01-2.09, $P=0.04)$ compared with E23E homozygotes, which did not change, even after adjustment for clinical factors like age, sex, fasting plasma glucose (FPG), $\mathrm{A}_{1 \mathrm{c}}$, BMI, age at diagnosis, and duration of diabetes (OR 1.69, 95\% CI 1.02-2.78, $P=0.04$ ). ${ }^{15} \mathrm{In}$ 477 Caucasian T2DM patients, the Gly972Arg polymorphism of the IRSI gene was found in $8.7 \%$ of well-controlled T2DM patients on oral therapy versus $16.7 \%$ in patients with secondary failure to SU. ${ }^{16}$ This SNP was associated with relative risk of $2.7(1.02-7.28, P=0.045)$ to $2.0(1.38-3.86, P=0.038)$ of secondary SU failure, which persisted even after adjustment for various clinical factors like age, sex, FPG, $\mathrm{A}_{1 \mathrm{c}}$, BMI, age at diagnosis, and duration of diabetes. ${ }^{16}$

KATP channels containing the K23/A1369 haplotype of the genes $K C N J 11$ and $A B C C 8$ were significantly less sensitive to inhibition by tolbutamide, chlorpropamide, and glimepiride and more sensitive to inhibition by mitiglinide and gliclazide when compared to the SNP E23/S1369. ${ }^{17}$ Nateglinide, glipizide, and glibenclamide showed similar inhibitory profiles in KATP channels containing either haplotype. $^{17}$

Carriers of the T-allele (TT + TG) of the SNP rs163184 $(\mathrm{T}>\mathrm{G})$ of another diabetes susceptibility gene expressed in $\beta$-cells $(K C N Q 1)$ achieved significantly lower FPG (6.95 mmol/L [125 mg/dL]) 6 months after therapy with SU in 87 T2DM patients uncontrolled on metformin monotherapy when compared to the GG genotype $(7.50 \mathrm{mmol} / \mathrm{L}$ [135 mg/dL]). ${ }^{18}$ In 367 Chinese T2DM patients on repaglinide, those with the rs2237892 risk C allele of the gene $K C N Q 1$ had a significantly lower fasting insulin (FI) and homeostasis model assessment of insulin resistance (HOMA-IR) levels than carriers of the T allele. ${ }^{19}$ Patients with the rs 2237895 risk $\mathrm{C}$ allele had significantly higher FPG, postprandial plasma glucose (PPPG), and HOMA-IR values when compared to patients with the A allele. Thus, response to repaglinide treatment may be better in patients with the rs2237892 $\mathrm{T}$ allele and rs $2237895 \mathrm{C}$ allele compared to those with the rs 2237892 CC and rs2237895 AA genotypes. ${ }^{19}$ Similarly, in 209 newly diagnosed T2DM Chinese patients given repaglinide for 48 weeks, the presence of the rs2237892 TT homozygotes showed a significantly lower PPPG $(P=0.03)$ when compared to the $\mathrm{C}$ allele carriers. ${ }^{20}$

To assess which other genetic polymorphisms are associated with metabolism of repaglinide, 368 Chinese patients with T2DM were compared to 132 healthy controls. ${ }^{21}$ The frequency of allele T45 of the gene NeuroD1/BETA2 was significantly higher in T2DM patients $(13.45 \%)$ than in the controls $(6.8 \%, P<0.01, \mathrm{OR}=2.342$ [95\% CI 1.365-4.019], $P=0.002$ ). Patients with the A45T polymorphism had higher FI and postprandial serum insulin (PPI) compared to the subjects with the $\mathrm{T}$ allele. These $\mathrm{T}$ allele subjects, after repaglinide therapy, were shown to have attenuated FPG and PPPG levels. ${ }^{21}$ In R121W R allele carriers of the PAX4 gene, the RR genotype had higher PPI levels and better lowering of both FPG and PPPG levels when compared to the R/W genotypes $(-6.53 \pm 6.52$ versus $-2.95 \pm 1.17 \mathrm{mmol} 1(-1), P<0.05) .{ }^{21}$ In 443 Chinese T2DM patients on repaglinide for 8 weeks and 229 healthy volunteers, rs 13266634 risk $\mathrm{C}$ allele of the gene $S L C 30 A 8$ was found in a significantly higher frequency in T2DM patients than in controls $(P<0.05){ }^{22}$ The rs 13266634 CT + TT genotypes had higher FI and PPI levels compared with CC genotype carriers. T2DM patients with rs 16889462 GA genotype of the gene $S L C 30 A 8$ showed a higher reduction 
in FPG, PPPG, and $A_{1 c}$ with repaglinide therapy compared with subjects with the GG genotype..$^{22}$

\section{Thiazolidinediones}

Thiazolidinediones act as insulin-sensitizers through activation of the transcription factor peroxisome proliferatoractivated receptor-gamma 2 (PPAR $\gamma 2$ ), which plays a pivotal role in adipocyte differentiation and expression of adipocytespecific genes. ${ }^{3}$ The efficacy of rosiglitazone ( $4 \mathrm{mg}$ /day for 12 weeks) in relation to PPAR $\gamma 2$ genetic variations was studied in 198 T2DM patients. ${ }^{23}$ The presence of the Ala12 allele lead to significantly lower FPG and $\mathrm{A}_{1 \mathrm{c}}(2.8 \mathrm{mmol} / \mathrm{L}$ [50.6 mg/dL] and $1.41 \%$ ) when compared to those without the allele $(1.3 \mathrm{mmol} / \mathrm{L}[24.3 \mathrm{mg} / \mathrm{dL}]$ and $0.57 \%$ reduction, $P=0.26$ and $P=0.01$, respectively). ${ }^{23}$ In addition, there was a significant difference in the response rate to rosiglitazone therapy between the Pro12Pro and the Pro12Ala variant groups $(43.72 \%$ versus $86.67 \%){ }^{23}$

In 250 Chinese T2DM patients on pioglitazone ( $30 \mathrm{mg}$ /day for 24 weeks), the Ala12Ala and Pro12Ala genotypes and Ala allele of the PPAR $\gamma$ gene were significantly more frequent in pioglitazone responders than in nonresponders $(26.0 \%$ versus $13.5 \%, P=0.025$ and $15.6 \%$ versus $7.3 \%, P=0.008) .{ }^{24}$ The decrease in FPG $(2.8 \mathrm{mmol} / \mathrm{L}[50.4 \mathrm{mg} / \mathrm{dL}]$ versus 2.4 $\mathrm{mmol} / \mathrm{L}[43.3 \mathrm{mg} / \mathrm{dL}], P<0.001)$ and $\mathrm{A}_{1 \mathrm{c}}(0.57 \%$ versus $0.35 \%, P=0.004)$ levels was significantly greater in subjects with the Pro12Ala and Ala12Ala carriers than in Pro12Pro carriers. On further analysis, only the PPAR $\gamma$ Pro12Ala polymorphism was found to be associated with the response to pioglitazone. ${ }^{24}$ This finding was not replicated in 113 T2DM patients from Germany, where both Pro12Ala and the Pro12Pro variants were not associated with response to pioglitazone. ${ }^{25}$ In 101 Iranian T2DM patients, even though the Pro12Ala genotype showed a better therapeutic response compared to the Pro12Pro genotype, the difference between groups was not statistical significance. ${ }^{26}$ However, a recent meta-analysis showed that patients with PPAR $\gamma$ gene Pro12Ala polymorphism had a more favorable change in FPG with pioglitazone $(P=0.018)$ when compared with the Pro12Pro genotype. ${ }^{27}$

In 197 Chinese Han T2DM patients of whom 67 patients were given pioglitazone (30 mg/day for 12 weeks), those patients with PPAR 2 gene polymorphism rs1801282 CG showed significantly higher levels of PPPG and serum triglyceride compared with those with rs $1801282 \mathrm{CC}$ genotype. ${ }^{28}$ In patients with protein tyrosine phosphatase receptor type $D$ gene polymorphism $\mathrm{rs} 17584499$, the CC genotype had better PPPG levels compared with CT + TT genotypes. ${ }^{28}$ In 241 Chinese patients with T2DM of whom 41 patients were given rosiglitazone ( $4 \mathrm{mg}$ daily for 12 weeks), the presence of the SNPs Thr394Thr and Gly482Ser of the PPAR Ycoactivator-1 gene increased the therapeutic efficacy of rosiglitazone when compared to controls. ${ }^{29}$

Other genes related to leptin, resistin, and adiponectin have been studied. In 245 Chinese patients with T2DM and 122 healthy volunteers, the frequency of the SNPs of the leptin gene G-2548A and TNF-alpha gene G-308A were the same..$^{30}$ At baseline in $42 \mathrm{~T} 2 \mathrm{DM}$ patients on rosiglitazone (4 mg daily for 8 weeks), those with the G allele of leptin $G-2548 A$ had a higher FPG levels compared to the AA genotypes $(P<0.05)$. The effect on FI and PPI were enhanced with rosiglitazone therapy in patients with AA genotype of leptin G-2548A when compared with GG + GA genotype. There was an attenuated effect on FI in patients with GA + AA genotype of TNF-alpha G-308A compared with GG genotype $(P<0.05){ }^{30}$

A prospective study of $121 \mathrm{~T} 2 \mathrm{DM}$ patients and retrospective data from $63 \mathrm{~T} 2 \mathrm{DM}$ patients treated with pioglitazone for 12 weeks revealed that the G/G but not C/G genotype of the resistin gene promoter SNP at -420 , rs $1862513 \mathrm{had}$ lower FPG $(P=0.020)$ and better HOMA-IR $(P=0.012)$ when compared to $\mathrm{C} / \mathrm{C}$ genotype. ${ }^{31}$ Patients on rosiglitazone monotherapy (4 mg daily for 12 weeks) with SNP rs $11377 \mathrm{CC}$ homozygote genotype and $45 \mathrm{TG}+\mathrm{GG}$ heterozygote genotype of the adiponectin common polymorphisms $45 \mathrm{~T} / \mathrm{G}$ and $-11377 \mathrm{C} / \mathrm{G}$ had a better response in FPG, PPPG, HOMA-IR, and serum adiponectin levels $(P=0.000)$ compared with $11377 \mathrm{CG}+\mathrm{GG}$ heterozygote and 45TT homozygote genotypes. ${ }^{32}$ This was contradicted in another study of Chinese T2DM patients, where the 11377CG genotype had a better response in FPG and $\mathrm{A}_{1 \mathrm{c}}$ when compared to the 11377 CC polymorphism. ${ }^{33}$ The presence of the two SNPs, 45T/G and 795G/A, in 101 Iranian patients with T2DM on pioglitazone for 12 weeks were not significantly associated with the response to pioglitazone. ${ }^{34}$

Genetic polymorphisms have been studied in other genes such as KCNQ1,UCP2, ADRB3, and $L P L$. The presence of rs2237897 allele of the KCNQ1 gene was associated with significant decrease in PPPG levels in 209 Chinese T2DM patients given rosiglitazone for 48 weeks. ${ }^{20}$ The frequency of the allele UCP2 $-866 \mathrm{G} / \mathrm{A}$ and $A D R B 3$ Trp64Arg genetic polymorphisms were the same in 472 Chinese T2DM patients and 321 healthy volunteers..$^{35}$ At baseline, the A allele carriers of UCP2 had significantly 
lower PPI (61.5 \pm 34.3 versus $41.6 \pm 28.7 \mathrm{mU} 1(-1), P<0.01)$ and low-density lipoprotein-cholesterol (LDL-C) (3.4 \pm 1.1 versus $2.7 \pm 1.1$ mmol $1(-1), P<0.05)$ compared with GG genotypes. After rosiglitazone $4 \mathrm{mg} /$ day for 12 weeks there was improvement in PPI $(-3.82 \pm 13.2$ versus $-42.1 \pm 30.7 \mathrm{mU}$ $1(-1), P<0.01)(9.45-51.31$ versus $0.48-11.88 \mathrm{mU} 1[-1])$ and greater attenuation of $\mathrm{A}_{1 \mathrm{c}}(-1.85 \pm 1.62$ versus $-0.61 \pm 0.80 \%, P<0.05)(0.14-1.37$ versus $1.10-2.38 \%)$ compared with GG genotypes. ${ }^{35}$ Patients with $A D R B 3$ Trp64Arg when compared with $A D R B 3$ Trp64Trp polymorphism had a better response in serum triglyceride, LDL-C, and adiponectin levels. ${ }^{35}$

In $113 \mathrm{~T} 2 \mathrm{DM}$ patients on pioglitazone $(30 \mathrm{mg} /$ day for 10 weeks), the presence of the SNP S447S genotype of the $L P L$ gene had a significantly better response in FPG and $\mathrm{A}_{1 \mathrm{c}}$ reduction, along with beneficial effects on lipid profile and blood pressure (BP) when compared to the S447X genotype. ${ }^{36}$

\section{Glucagon-like peptide-I analogs and dipeptidyl peptidase-4 inhibitors incretins}

Glucagon-like peptide-1 (GLP-1) analogs and dipeptidyl peptidase-4 (DPP-4) inhibitors, through their receptors on pancreatic $\alpha / \beta$ cells, stimulate the synthesis of insulin and suppress glucagon levels. ${ }^{37}$ The speculation is that any of the genetic variants which affect insulin synthesis/secretion may also affect the incretin response. ${ }^{38}$

The effect of 21 SNPs in GLP-1 receptor gene on insulin secretion was studied in 88 healthy young individuals, using a hyperglycemic clamp with GLP-1 being infused for the last 2 hours. $^{37}$ Two of 21 SNPs (rs6923761 and rs3765467) were associated with altered response of the $\beta$-cell to the GLP-1 infusion, which may indicate that variations in the GLP-1 receptor may alter insulin secretion in response to exogenous GLP-1. ${ }^{37}$ However, this needs to be confirmed in T2DM patients with larger studies.

In 1,578 German subjects at high risk to develop diabetes, the effect of KCNQ1 gene SNPs rs151290, rs2237892, rs2237895, and rs2237897 on insulin secretion in response to oral glucose tolerance test (OGTT), intravenous GTT (IVGTT), and to hyperglycemic clamp combined with GLP-1 and arginine administration was studied. ${ }^{38}$ Insulin secretion was lower in homozygous major allele carriers of SNPs, rs151290, rs2237892, and rs2237897 while the $\beta$-cell function was improved in homozygous major allele carriers of rs2237895 (AA). However, during the hyperglycemic clamp combined with GLP-1 administration, there were no associations found between the $K C N Q 1$ variants and glucose, GLP-1, and insulin secretion. ${ }^{38}$ In a subset of patients, there was a significant increase in OGTT-stimulated gastric inhibitory polypeptide (GIP) levels $(P=0.019)$ with the SNP rs151290, even after adjustment for sex, age, and BMI. This may suggest that an altered incretin secretion after food intake provides a potential link between $K C N Q 1$ gene variants and impaired $\beta$-cell function. This effect was not found with other variants, rs2237892, rs2237895, and rs2237897, and the authors concluded that this could be secondary to limited sample size or that these $K C N Q 1$ variants regulate insulin secretion differently than rs $151290 .^{38}$

The transcription factor T-cell factor 7-like-2 (TCF7L2) is an essential factor for GLP-1 secretion from intestinal L-cells. ${ }^{39}$ The interaction between TCF7L2 and GLP-1/GIP receptors is important for $\beta$-cell function. ${ }^{40}$ When islet cells of patients with T2DM were treated with small interfering RNA to TCF7L2, the expression of the GLP-1 and GIP receptors were decreased, and there was impaired insulin secretion when stimulated by glucose and GLP-1/GIP. ${ }^{39}$ Of the five SNPs in the TCF 7L2 gene which were genotyped in 1,110 nondiabetic German participants, there was a significant reduction in GLP-1-induced insulin secretion in carriers of rs7903146 and rs12255372 $(P<0.02)$, which may be the result of a functional defect in GLP-1 signaling in $\beta$-cells rather than a reduction in GLP- 1 secretion. ${ }^{40}$ In the presence of TCF7L2 gene variants (TT or TC at rs7903146) in eight subjects with high risk to develop T2DM, the $\beta$-cell response to OGTT was $50 \%$ lower $\left(47 \pm 4\right.$ versus $95 \pm 15 \times 10^{9}$ $\min (-1), P=0.01)$, and the incretin effect was also reduced by $30 \%(32 \% \pm 4 \%$ versus $46 \% \pm 4 \%, P=0.02)$ when compared to ten matched subjects with wild-type genotype, while the response was similar in both groups to IVGTT. ${ }^{41}$ The lower incretin effect occurred in spite of having the same level of GLP-1/GIP secretion to oral glucose in both groups, indicating that it may be secondary to the effect of TCF7L2 gene variants on the sensitivity of the $\beta$-cell to incretins. ${ }^{41}$

The WFS1 gene plays a significant role in the maintenance of homeostasis of the endoplasmic reticulum in pancreatic $\beta$-cells. ${ }^{42}$ In 1,578 subjects with high risk to develop T2DM, the SNP rs10010131 of the WFS1 gene was associated with reduced OGTT and GLP-1 infusion combined with a hyperglycemic clamp-derived insulin secretion $(P=0.03)$, with no difference between groups in IVGTT and hyperglycemic clamp. ${ }^{42}$ 
Gene variants of JAZF1, CDC123/CAMK1D, TSPAN8/ LGR5, THADA, ADAMTS9, NOTCH2/ADAMS30, DCD, VEGFA, BCL11A, HNF1B, WFS1, and MTNR1B were evaluated in a study with 180 subjects with normal glucose tolerance and 156 subjects with impaired glucose tolerance. ${ }^{43}$ Certain gene variants in $C D C 123 / C A M K 1 D$, ADAMTS9, BCL11A, and MTNR1B affected various aspects of the insulin response to glucose (all $P<6.9 \times 10^{-3}$ ) while the THADA gene variant was associated with lower $\beta$-cell response to GLP-1 and arginine (both $P<1.6 \times 10^{-3}$ ). In carriers of MTNR1B, the trend seen toward an increased insulin response to GLP-1 $(P=0.03)$, if confirmed, may be important clinically. ${ }^{43}$

The SNPs of the gene $A B C B 1, \mathrm{CGC} / \mathrm{CGC}, \mathrm{CGC} / \mathrm{TTT}$, and TTT/TTT, did not influence sitagliptin pharmacokinetics in ten healthy volunteers. ${ }^{44}$ Various SNPs of the DPP-4 enzyme genes, g-234A/C, rs13015258, IVS8-128A/G, rs17848920, IVS8 + 46C/T, rs10930040, IVS11-143A/G, rs2302873, G645G, rs17848910, IVS22 + 4C/T, and rs2268891, studied to assess the efficacy of vildagliptin, showed no significant associations, and the authors hypothesized that it could be secondary to a small sample size. ${ }^{45}$ DPP-4 gene variants could affect the efficacy of the DPP-4 inhibitors; however, there is no study currently proving that a patient with a specific variant in a specific gene shows a better response to a particular DPP-4 inhibitor. The presence or absence of genetic variants regarding clinical response to incretin therapy, if predictive, could lead to cost savings.

\section{Sodium glucose transport 2 inhibitors}

Sodium glucose transport 2 (SGLT2) inhibitors block the reabsorption of filtered glucose, leading to glucosuria, with improvements in glycemic control and weight loss. The SGLT2 gene (SLC5) has been mapped to chromosome $16 \mathrm{p} 11.2,{ }^{46}$ and up to 50 different mutations of this gene have been reported and lead to familial renal glucosuria..$^{47,48}$ Genotyping for four common genetic variations in the SLC5 gene in 1,013 nondiabetic German subjects showed that the SNP rs $9934336 \mathrm{G}$ allele was found with increased 30-minute plasma glucose, 120-minute insulin concentrations, and 120 -minute area under the curve glucose during OGTT. ${ }^{49}$ In 2,590 nondiabetic subjects from Berlin, there was a nominal association with the 120-minute insulin concentrations, suggesting a possible role in the regulation of glucose homeostasis for SLC5 gene variants. ${ }^{49}$ So far, there have been no definitive studies of patients with T2DM regarding the genetic variants and SNPs associated with response to the SGLT2 inhibitors.

\section{Canagliflozin: role of clinical profiling - efficacy and adverse events data Effect on glycemic parameters and weight}

In multiple Phase III studies lasting from 26-52 weeks, a total of 4,978 patients who were either treatment-naïve or on mono/dual oral agents were randomized to canagliflozin 100 and $300 \mathrm{mg}$ daily versus placebo, glimiperide, and sitagliptin..$^{50-55}$ The placebo-corrected reduction in $\mathrm{A}_{1 \mathrm{c}}$, FPG, and PPPG with canagliflozin 100 and $300 \mathrm{mg}$ were significant. The $\mathrm{A}_{1 \mathrm{c}}$ reductions with canagliflozin 100 and $300 \mathrm{mg}$ ranged from $0.63-0.91 \%$ versus $0.97-1.16 \%$, respectively. ${ }^{50-52}$ The FBG and PPBG reductions with cangliflozin $100 \mathrm{mg}$ and $300 \mathrm{mg}$ ranged from $1.2-2.0 \mathrm{mmol} / \mathrm{L}(21.6-36 \mathrm{mg} / \mathrm{dL})$ and $2.7 \mathrm{mmol} / \mathrm{L}(48.6 \mathrm{mg} / \mathrm{dL})$ versus $1.92-2.4 \mathrm{mmol} / \mathrm{L}$ $(34.5-43.2 \mathrm{mg} / \mathrm{dL})$ and $3.6 \mathrm{mmol} / \mathrm{L}(63.8 \mathrm{mg} / \mathrm{dL})$, respectively. ${ }^{50-52}$ Weight loss of $1.4-3.0 \mathrm{~kg}$ was found with canagliflozin $100 \mathrm{mg}$ and $2.0-3.8 \mathrm{~kg}$ with canagliflozin $300 \mathrm{mg}$. The decrease in $\mathrm{A}_{1 \mathrm{c}}$ was similar between treatmentnaïve patients and those already on oral antihyperglycemic therapy. ${ }^{50-52}$

The mean $\mathrm{A}_{1 \mathrm{c}}$ and FPG reduction with the canagliflozin $100 \mathrm{mg}$ dose was noninferior to glimiperide, $0.82 \%$ and $0.81 \%$ and 1.4 and $1.0 \mathrm{mmol} / \mathrm{L}(25.2$ and $18 \mathrm{mg} / \mathrm{dL})$, respectively, while the canagliflozin $300 \mathrm{mg}$ group showed superiority $(0.93 \%$ and $1.5 \mathrm{mmol} / \mathrm{L}[27 \mathrm{mg} / \mathrm{dL}]$ reduction, respectively). ${ }^{53}$ The $\mathrm{A}_{1 \mathrm{c}}$ reduction was sustained for 52 weeks in the canagliflozin groups while it started to rise after week 18 in the glimiperide group. A mean weight reduction of $4.2-4.7 \mathrm{~kg}$ was noted with canagliflozin compared to 1.0 $\mathrm{kg}$ weight gain with glimiperide and was predominantly from fat mass as shown by a reduced percent total fat, ${ }^{53,56}$ and accounted for two-thirds of the overall reduction, with slightly greater reductions in visceral fat. ${ }^{56}$ In the first study, where canagliflozin was compared to sitagliptin, there was a mean reduction in $\mathrm{A}_{1 \mathrm{c}}$ and $\mathrm{FPG}$ in the canagliflozin (1.03\% and $1.7 \mathrm{mmol} / \mathrm{L}[30.6 \mathrm{mg} / \mathrm{dL}])$ versus sitagliptin $(0.66 \%$ and $0.3 \mathrm{mmol} / \mathrm{L}[5.4 \mathrm{mg} / \mathrm{dL}]) .{ }^{56} \mathrm{As}$ with $\mathrm{SU}$, there was an increase in $\mathrm{A}_{1 \mathrm{c}}$ after week 12 in the sitagliptin group. A mean weight reduction of $2.5 \mathrm{~kg}$ was noted with canagliflozin compared to $0.3 \mathrm{~kg}$ weight gain with sitagliptin. The $\mathrm{A}_{1 \mathrm{c}}$ goals of $<7 \%$ were reached in $47.6 \%$ with canagliflozin and $35.3 \%$ with sitagliptin. ${ }^{54}$ In the second study at week 52 , the mean $\mathrm{A}_{1 \mathrm{c}}$ reduction in canagliflozin 100 and $300 \mathrm{mg}$ versus sitagliptin was comparable. Body weight decreased in canagliflozin 100 and $300 \mathrm{mg}(3.8 \%-4.2 \%)$ versus sitagliptin $(1.3 \%) .{ }^{55}$ 
Data of 2,313 patients $(1,868<65$ years and $445>65$ years $)$ from four Phase III studies showed that canagliflozin was efficacious in attaining a reduction in $\mathrm{A}_{1 \mathrm{c}}$, FPG, body weight, and systolic BP (SBP) in both groups when compared to placebo. ${ }^{57}$ However, data extraction from 15 clinical trials showed that in elderly T2DM patients, the $\mathrm{A}_{1 \mathrm{c}}$ reduction was lower with canagliflozin when compared to younger population, while the reduction in SBP and weight was the same. ${ }^{58}$ In multiple Phase III studies, there was a significant increase in $\beta$-cell glucose sensitivity compared to placebo with canagliflozin, and it was noninferior to sitagliptin. This indicates that canagliflozin given for 26-52 weeks improved measures of $\beta$-cell function. ${ }^{59}$

\section{Effect on BP, pulse rate, and lipids}

Canagliflozin showed a significant reduction in the placebocorrected mean SBP and diastolic BP in both dose groups, ranging from $1.62-10.7 \mathrm{mmHg}$ and $1.6-7.0 \mathrm{mmHg}$, respectively. ${ }^{50-52}$ Canagliflozin showed a mean decrease in SBP $(3.3-5.1 \mathrm{mmHg})$ versus an increase in the glimiperide $(0.2 \mathrm{mmHg})$ and sitagliptin $(0.9 \mathrm{mmHg})$ groups ${ }^{53,54}$ Both canagliflozin groups showed a placebo-corrected significant increase in high-density lipoprotein-cholesterol (HDL-C) levels $(2.3 \%-10.7 \%),{ }^{50,51}$ with triglycerides showing a minimal decrease $(0.6 \%-12.8 \%),{ }^{50,51}$ and LDL-C showed an increase $(1.9 \%-10.9 \%)$ in most studies. ${ }^{50-53}$ When canagliflozin 100 and $300 \mathrm{mg}$ was compared to glimiperide, there was an increase in HDL-C of $7.9 \%, 9.0 \%$, and $0.3 \%$, respectively, while the triglycerides showed a decrease of $3.7 \%$ in the canagliflozin $100 \mathrm{mg}$ group compared to an increase of $2.3 \%$ and $9.5 \%$ in the canagliflozin $300 \mathrm{mg}$ and glimiperide groups, respectively. ${ }^{53}$ Similarly, HDL-C increased in the pooled canagliflozin groups (7.6\%) compared to sitagliptin $(0.6 \%)$ while triglycerides showed an increase in both canagliflozin $300 \mathrm{mg}$ (9.6\%) and sitagliptin (11.9\%). ${ }^{54} \mathrm{An}$ increase in LDL-C was also seen in both canagliflozin $300 \mathrm{mg}(11.7 \%)$ and sitagliptin $(5.2 \%)$ groups. ${ }^{54}$

\section{Adverse events}

In Phase III studies, the incidence of adverse events (AEs) were similar between canagliflozin $(50 \%-77 \%)$ versus placebo $(53 \%-66 \%)^{51,52}$ versus glimiperide (68\%) and sitagliptin (77.5\%). ${ }^{53,54}$ Mild to moderate hypoglycemia episodes were higher in the pooled canagliflozin $(0 \%-28 \%)$ versus placebo $(2 \%),{ }^{50-52}$ while it was lower $(4.6 \%-5.6 \%)$ when compared to glimiperide $(34.2 \%)^{53}$ and similar to sitagliptin. ${ }^{55}$ There were no severe hypoglycemic events reported in most studies. ${ }^{50,52-54}$ Only small changes from baseline for serum creatinine, blood urea nitrogen, and serum urate were seen with canagliflozin relative to placebo. ${ }^{50,53}$ Small increases in hemoglobin were observed with canagliflozin (3.6\% and 3.9\%), whereas a slight decrease was observed with placebo $(0.2 \%) .{ }^{50}$ Increased urinary frequency was low in the pooled canagliflozin groups $(2.4 \%-5.3 \%)$ versus placebo $(0 \%-0.5 \%){ }^{51-54}$ The incidence of serious AEs were similar in the pooled canagliflozin groups $(2.1 \%-4.1 \%)$ versus placebo (1\%-5.8\%). ${ }^{50-52}$ Two deaths occurred during the treatment period, one each in the placebo and canagliflozin $100 \mathrm{mg}$ group, and were deemed not to be drug related. ${ }^{50}$ The incidence of serious AEs when compared to glimiperide and sitagliptin were similar. ${ }^{53,54}$ There were no cardiovascular (CV) AEs reported in any study. ${ }^{50-54}$ AEs secondary to reduced intravascular volume such as postural dizziness/orthostatic hypotension were low $(\leq 3 \%)$.

The incidence of overall AEs were the same in patients $<65$ and $\geq 65$ years of age. ${ }^{57}$ Serious AEs and AE-related discontinuations were higher in canagliflozin $100 \mathrm{mg}$ in the $\geq 65$ year-old patient group. The incidence of genital mycotic infections and osmotic diuresis-related AEs were higher with canagliflozin in both age groups. Incidences of urinary tract infections (UTIs), renal-related AEs, AEs related to volume depletion, lipid parameters, and documented hypoglycemia episodes were similar in both groups, indicating that it was generally well tolerated in older T2DM patients. ${ }^{57}$

When T2DM patients on hydrochlorothiazide (HCTZ) were given canagliflozin, the change in 24-hour urine volume from baseline was $-0.1 \mathrm{~L}$ with canagliflozin alone and $0.4 \mathrm{~L}$ with HCTZ alone and with canagliflozin + HCTZ. ${ }^{60}$ Most AEs were mild and higher with canagliflozin + HCTZ (69\%) than with canagliflozin (47\%) or HCTZ (50\%) alone. There were minimal changes in serum electrolytes with canagliflozin + HCTZ compared with individual treatments. Canagliflozin coadministered with HCTZ was generally well tolerated. ${ }^{60}$ Similarly, 36 T2DM patents on angiotensin-converting enzyme inhibitors or angiotensin receptor blockers given canagliflozin showed a modest increase in urine volume initially which was attenuated at the end of the study. ${ }^{61}$ Measures of volume status which were modestly increased at the beginning remained elevated till the end. ${ }^{61}$

In pooled data from Phase III studies, the incidence of female and male genital mycotic infections in 2,313 and 9,439 T2DM patients exposed to canagliflozin for 24 and 68 weeks, respectively, were studied. ${ }^{62}$ In the first group, the incidence of genital mycotic infections was higher in females compared to males for both canagliflozin $100(10.4 \%$ and $4.2 \%)$ and canagliflozin $300 \mathrm{mg}(11.4 \%$ and $3.7 \%)$ versus 
placebo (3.2\% and $0.6 \%$ ). In the second group, with 68 weeks exposure to canagliflozin, the incidence for canagliflozin 100 and $300 \mathrm{mg}$ versus placebo was females: $14.7 \%, 13.9 \%$, $3.1 \%$ versus males: $7.3 \%, 9.3 \%, 1.6 \%$, respectively. Most were mild to moderate in intensity, occurred within the first 4 months in females and first year in males, none were serious, few led to discontinuation, few patients had $>1$ event (females, 2.3\%; males, 0.9\%), were not dose dependent, and responded to standard treatments. ${ }^{62}$

\section{Clinical profiling of canagliflozin}

Based on the available data regarding the mechanism of canagliflozin, its efficacy, and safety, the clinician may attempt to find the ideal T2DM patient for whom it may lead to certain benefits. As it acts independent of $\beta$-cell function or mass and insulin sensitivity, canagliflozin can be used at any stage of T2DM, any age, irrespective of the duration of diabetes and in combination with all other oral agents and insulin. Ideally, patients who need an $\mathrm{A}_{1 \mathrm{c}}$ lowering from $0.5 \%$ to $1.17 \%$ may benefit from its use. ${ }^{50-54}$ It may be used as a second line agent in obese T2DM patients who need weight loss with fat mass reductions. In addition, the use of canagliflozin in patients on oral SU and/or insulin therapy may help to attenuate the weight gain associated with these agents. Additional benefits seen are $\mathrm{BP}$ reductions due to a diuretic effect, which appear to be safe, and may allow more T2DM patients to reach the goal BP with or without reduction in dose of antihypertensive medications.

It is unclear at this point if there is a clinical implication of increase in LDL-C levels associated with canagliflozin therapy on $\mathrm{CV}$ risk. At this time, it would be prudent to keep a close watch on the LDL-C levels and adjust statin therapy accordingly to maintain LDL goals and await the results of long-term CV studies like the Canagliflozin cardioVascular Assessment Study.

It may thus be appropriate at the present time to be cautious about starting canagliflozin therapy in patients with a heavy preexisting CV burden. Even though UTIs and genital infections were mild to moderate in nature and the same in the $<65$ and $>65$ year age groups, it may be prudent to avoid using it in patients with preexisting repeated episodes of candidiasis and/or UTIs, and the consequences of treatment of these AEs may discourage the use of canagliflozin in the elderly patient. Increased urinary frequency in the less mobile elderly may lead to discomfort.

\section{Discussion}

The importance of genetic variants was shown in the monogenic forms of diabetes. The clinical implication of finding these single gene diabetes disorders is that the physicians can be certain that oral antihyperglycemic agents rather that insulin therapy can be used successfully to treat such patients. However, as monogenic diabetes is found only in a small percentage of patients, a similar discovery of genetic variants, which can guide and individualize diabetes therapy in the more common T2DM that is multifactorial in origin, would be clinically significant. Genome-wide association studies have opened the door for patient profiling and research into genetic variants in multifactorial T2DM.

Another push for individualized management is that drug costs account for a large portion of the health expenditure in the US. The response to drugs is not always the same even in T2DM patients with similar phenotypes. At present, most physicians follow an algorithmic approach to T2DM treatment. A prior knowledge of the drug response in a particular patient based on pharmacogenomics can lead to a more efficient use of the appropriate drugs. It would guide physicians in providing patients with the most effective treatment strategy given their individual genetic background and avoid drug side effects in the process.

It appeared that oral antihyperglycemic therapy was more effective in the presence of certain genotypes. Clinically, it may be possible to tailor the type of medication used based on the presence or absence of the various genetic variants and thus identify patients who will have the highest benefit from these agents. It appears that most of the information on genetic variants and response to meglitinides and thiazolidinedione therapy comes from the Chinese and Japanese populations, which raises the question about its applicability to other ethnic groups.

A number of the genes are involved in drug metabolism in T2DM patients, and some of the information available in the literature needs further validation to ensure its authenticity. There are several studies whose findings have not been replicated and, at present, cannot confirm association. The polymorphisms studied may only explain some of the variability in response to T2DM drug therapy. There are still unidentified factors including racial differences which appear to play a role in the interindividual variability seen in clinical practice. For example, the SNP CYP2C8*3 was found in higher frequency in Caucasians $(10 \%-23 \%),{ }^{63}$ followed by Hispanics, and is rare among people with African and Asian ancestry. ${ }^{63,64}$ The present studies have been done in certain ethnic groups, and further well-designed studies are needed to cover other ethnic groups found in the US and the rest of the world. Further studies to detect other genetic factors which may better explain the variability in drug treatment response is needed. 
Advances in T2DM genetics may in the future improve disease prediction, prevention, and treatment. A barrier to the implementation of routine genetic testing may be the acceptance by physicians and patients. A recent survey of a sample of 304 nationally representative US primary care physicians and endocrinologists, 152 nondiabetic primary care patients, and 89 patients enrolled in a diabetes pharmacogenetics study was done to assess their reactions to genetic testing for T2DM. ${ }^{65}$ Both physicians (79\%) and patients (80\%) favored genetic testing for diabetes risk prediction. About $71 \%$ of patients versus $23 \%$ of physicians indicated that a "high risk" result would be very likely to improve motivation to adopt preventive lifestyle changes. In addition, more patients favored genetic testing to guide therapy (78\%) versus physicians (48\%) and reported that genetic testing would make them "much more motivated" to adhere to medications (72\%). Both physicians and patients have high expectations that genetic testing would improve patient motivation to control T2DM and can possibly motivate behavior change compared with standard risk information. ${ }^{65}$ Regarding canagliflozin, until we have well-performed genetic studies, the decision to use canagliflozin or any other SGLT2 inhibitor should be individualized based on the health and presence of comorbid conditions on a case by case basis, especially in the older age patient groups. Adequate education should be provided to all patients prior to starting canagliflozin.

\section{Conclusion}

The potential exists for pharmacogenomics to promote efficacious, safe, and cost-effective, individualized diabetes management. However, pharmacogenomics is still in its early stages, and the idea of defining patients genetically to predict individual responses to drugs and obtain safe and effective T2DM management is promising in spite of existing barriers. Currently, clinical profiling of patients with T2DM and using an individualized approach with most drugs, including canagliflozin, based on comorbid conditions still remains the most accepted approach for the management of T2DM.

\section{Disclosure}

The author reports no conflicts of interest in this work.

\section{References}

1. Ali MK, McKeever Bullard K, Imperatore G, Barker L, Gregg EW; Centers for Disease Control and Prevention (CDC). Characteristics associated with poor glycemic control among adults with self-reported diagnosed diabetes - National Health and Nutrition Examination Survey, United States, 2007-2010. MMWR Morb Mortal Wkly Rep. Suppl 61:32-37.
2. Inzucchi SE, Bergenstal RM, Buse JB, et al; American Diabetes Association (ADA); European Association for the Study of Diabetes (EASD). Management of hyperglycemia in type 2 diabetes: a patientcentered approach: position statement of the American Diabetes Association (ADA) and the European Association for the Study of Diabetes (EASD). Diabetes Care. 2012;35(6):1364-1379.

3. Inzucchi SE. Oral antihyperglycemic therapy for type 2 diabetes: scientific review. JAMA. 2002;287(3):360-372.

4. Donnelly LA, Doney AS, Hattersley AT, Morris AD, Pearson ER. The effect of obesity on glycaemic response to metformin or sulphonylureas in Type 2 diabetes. Diabet Med. 2006;23(2):128-133.

5. Graham GG, Punt J, Arora M, et al. Clinical pharmacokinetics of metformin. Clin Pharmacokinet. 2011;50(2):81-98.

6. Otsuka M, Matsumoto T, Morimoto R, Arioka S, Omote H, Moriyama Y. A human transporter protein that mediates the final excretion step for toxic organic cations. Proc Natl Acad Sci U S A. 2005;102(50):17923-17928.

7. Becker ML, Visser LE, van Schaik RH, Hofman A, Uitterlinden AG, Stricker BH. Genetic variation in the organic cation transporter 1 is associated with metformin response in patients with diabetes mellitus. Pharmacogenomics J. 2009;9(4):242-247.

8. Tanihara Y, Masuda S, Sato T, Katsura T, Ogawa O, Inui K. Substrate specificity of MATE1 and MATE2-K, human multidrug and toxin extrusions/H(+)organic cation antiporters. Biochem Pharmacol. 2007;74(2):359-371.

9. Shikata E, Yamamoto R, Takane H, et al. Human organic cation transporter (OCT1 and OCT2) gene polymorphisms and therapeutic effects of metformin. J Hum Genet. 2007;52(2):117-122.

10. Zhou K, Bellenguez C, Spencer CC, et al; GoDARTS and UKPDS Diabetes Pharmacogenetics Study Group; Wellcome Trust Case Control Consortium 2; MAGIC investigators. Common variants near ATM are associated with glycemic response to metformin in type 2 diabetes. Nat Genet. 2011;43(2):117-120.

11. Christensen MM, Brasch-Andersen C, Green H, et al. The pharmacogenetics of metformin and its impact on plasma metformin steady-state levels and glycosylated hemoglobin A1c. Pharmacogenet Genomics. 2011;21(12):837-850.

12. Lavrenko AV, Shlykova OA, Kutsenko LA, Mamontova TV, Kaĭdashev IP. [Pharmacogenetic features of the effect of metformin in patients with coronary heart disease in the presence of metabolic syndrome and type 2 diabetes mellitus in terms of PPAR-gamma2 gene polymorphism]. Ter Arkh. 2012;84(9):35-40. Russian.

13. Pearson ER, Liddell WG, Shepherd M, Corrall RJ, Hattersley AT. Sensitivity to sulphonylureas in patients with hepatocyte nuclear factor-1 alpha gene mutations: evidence for pharmacogenetics in diabetes. Diabet Med. 2000;17(7):543-545.

14. Javorsky M, Klimcakova L, Schroner Z, et al. KCNJ11 gene E23K variant and therapeutic response to sulfonylureas. Eur J Intern Med. 2012;23(3):245-249.

15. Sesti G, Laratta E, Cardellini M, et al. The E23K variant of KCNJ11 encoding the pancreatic beta-cell adenosine 5 'triphosphate-sensitive potassium channel subunit Kir6.2 is associated with an increased risk of secondary failure to sulfonylurea in patients with type 2 diabetes. J Clin Endocrinol Metab. 2006;91(6):2334-2339.

16. Sesti G, Marini MA, Cardellini M, et al. The Arg972 variant in insulin receptor substrate-1 is associated with an increased risk of secondary failure to sulfonylurea in patients with type 2 diabetes. Diabetes Care. 2004;27(6):1394-1398.

17. Lang VY, Fatehi M, Light PE. Pharmacogenomic analysis of ATP-sensitive potassium channels coexpressing the common type 2 diabetes risk variants E23K and S1369A. Pharmacogenet Genomics. 2012;22(3):206-214.

18. Schroner Z, Dobrikova M, Klimcakova L, et al. Variation in KCNQ1 is associated with therapeutic response to sulphonylureas. Med Sci Monit. 2011;17(7):CR392-CR396.

19. Dai XP, Huang Q, Yin JY, et al. KCNQ1 gene polymorphisms are associated with the therapeutic efficacy of repaglinide in Chinese type 2 diabetic patients. Clin Exp Pharmacol Physiol. 2012;39(5): $462-468$. 
20. Yu W, Hu C, Zhang R, et al. Effects of KCNQ1 polymorphisms on the therapeutic efficacy of oral antidiabetic drugs in Chinese patients with type 2 diabetes. Clin Pharmacol Ther. 2011;89(3):437-442.

21. Gong ZC, Huang Q, Dai XP, et al. NeuroD1 A45T and PAX4 R121W polymorphisms are associated with plasma glucose level of repaglinide monotherapy in Chinese patients with type 2 diabetes. Br J Clin Pharmacol. 2012;74(3):501-509.

22. Huang Q, Yin JY, Dai XP, et al. Association analysis of SLC30A8 rs13266634 and rs16889462 polymorphisms with type 2 diabetes mellitus and repaglinide response in Chinese patients. Eur J Clin Pharmacol. 2010;66(12):1207-1215.

23. Kang ES, Park SY, Kim HJ, et al. Effects of Pro12Ala polymorphism of peroxisome proliferator-activated receptor gamma2 gene on rosiglitazone response in type 2 diabetes. Clin Pharmacol Ther. 2005;78(2):202-208.

24. Hsieh MC, Lin KD, Tien KJ, et al. Common polymorphisms of the peroxisome proliferator-activated receptor-gamma (Pro12Ala) and peroxisome proliferator-activated receptor-gamma coactivator-1 (Gly482Ser) and the response to pioglitazone in Chinese patients with type 2 diabetes mellitus. Metabolism. 2010;59(8):1139-1144.

25. Blüher M, Lübben G, Paschke R. Analysis of the relationship between the Pro12Ala variant in the PPAR-gamma2 gene and the response rate to therapy with pioglitazone in patients with type 2 diabetes. Diabetes Care. 2003;26(3):825-831.

26. Namvaran F, Azarpira N, Rahimi-Moghaddam P, Dabbaghmanesh MH. Polymorphism of peroxisome proliferator-activated receptor $\gamma(\operatorname{PPAR} \gamma)$ Pro12Ala in the Iranian population: relation with insulin resistance and response to treatment with pioglitazone in type 2 diabetes. Eur $J$ Pharmacol. 2011;671(1-3):1-6.

27. Kawaguchi-Suzuki M, Frye RF. Current clinical evidence on pioglitazone pharmacogenomics. Front Pharmacol. 2013;4:147.

28. Pei Q, Huang Q, Yang GP, et al. PPAR- $\gamma 2$ and PTPRD gene polymorphisms influence type 2 diabetes patients' response to pioglitazone in China. Acta Pharmacol Sin. 2013;34(2):255-261.

29. Zhang KH, Huang Q, Dai XP, et al. Effects of the peroxisome proliferator activated receptor- $\gamma$ coactivator- $1 \alpha(\mathrm{PGC}-1 \alpha)$ Thr394Thr and Gly482Ser polymorphisms on rosiglitazone response in Chinese patients with type 2 diabetes mellitus. J Clin Pharmacol. 2010;50(9): $1022-1030$.

30. Liu HL, Lin YG, Wu J, et al. Impact of genetic polymorphisms of leptin and TNF-alpha on rosiglitazone response in Chinese patients with type 2 diabetes. Eur J Clin Pharmacol. 2008;64(7):663-671.

31. Makino H, Shimizu I, Murao S, et al. A pilot study suggests that the G/G genotype of resistin single nucleotide polymorphism at -420 may be an independent predictor of a reduction in fasting plasma glucose and insulin resistance by pioglitazone in type 2 diabetes. Endocr $J$. 2009;56(9):1049-1058.

32. Sun $\mathrm{H}$, Gong $\mathrm{ZC}$, Yin JY, et al. The association of adiponectin allele $45 \mathrm{~T} / \mathrm{G}$ and $-11377 \mathrm{C} / \mathrm{G}$ polymorphisms with Type 2 diabetes and rosiglitazone response in Chinese patients. Br J Clin Pharmacol. 2008;65(6):917-926.

33. Li Z, Peng X, Wu Y, Xia Y, Liu X, Zhang Q. The influence of adiponectin gene polymorphism on the pioglitazone response in the Chinese with type 2 diabetes. Diabetes Obes Metab. 2008;10(9):794-802.

34. Namvaran F, Rahimi-Moghaddam P, Azarpira N, Dabbaghmanesh MH. Polymorphism of adiponectin $(45 \mathrm{~T} / \mathrm{G})$ and adiponectin receptor-2 (795G/A) in an Iranian population: relation with insulin resistance and response to treatment with pioglitazone in patients with type 2 diabetes mellitus. Mol Biol Rep. 2012;39(5):5511-5518.

35. Yang M, Huang Q, Wu J, et al. Effects of UCP2 -866 G/A and ADRB3 Trp64Arg on rosiglitazone response in Chinese patients with Type 2 diabetes. Br J Clin Pharmacol. 2009;68(1):14-22.

36. Wang G, Wang X, Zhang Q, Ma Z. Response to pioglitazone treatment is associated with the lipoprotein lipase S447X variant in subjects with type 2 diabetes mellitus. Int J Clin Pract. 2007;61(4): $552-557$.
37. Sathananthan A, Man CD, Micheletto F, et al. Common genetic variation in GLP1R and insulin secretion in response to exogenous GLP-1 in nondiabetic subjects: a pilot study. Diabetes Care. 2010;33(9): 2074-2076.

38. Müssig K, Staiger H, Machicao F, et al. Association of type 2 diabetes candidate polymorphisms in KCNQ1 with incretin and insulin secretion. Diabetes. 2009;58(7):1715-1720.

39. Shu L, Matveyenko AV, Kerr-Conte J, Cho JH, McIntosh CH, Maedler K. Decreased TCF7L2 protein levels in type 2 diabetes mellitus correlate with downregulation of GIP- and GLP-1 receptors and impaired betacell function. Hum Mol Genet. 2009;18(13):2388-2399.

40. Schäfer SA, Tschritter O, Machicao F, et al. Impaired glucagonlike peptide-1-induced insulin secretion in carriers of transcription factor 7-like 2 (TCF7L2) gene polymorphisms. Diabetologia. 2007;50(12):2443-2450.

41. Villareal DT, Robertson H, Bell GI, et al. TCF7L2 variant rs7903146 affects the risk of type 2 diabetes by modulating incretin action. Diabetes. 2010;59(2):479-485.

42. Schäfer SA, Müssig K, Staiger $\mathrm{H}$, et al. A common genetic variant in WFS1 determines impaired glucagon-like peptide-1-induced insulin secretion. Diabetologia. 2009;52(6):1075-1082.

43. Simonis-Bik AM, Nijpels G, van Haeften TW, et al. Gene variants in the novel type 2 diabetes loci CDC123/CAMK1D, THADA, ADAMTS9, BCL11A, and MTNR1B affect different aspects of pancreatic beta-cell function. Diabetes. 2010;59(1):293-301.

44. Aquilante CL, Wempe MF, Sidhom MS, Kosmiski LA, Predhomme JA. Effect of ABCB1 polymorphisms and atorvastatin on sitagliptin pharmacokinetics in healthy volunteers. Eur J Clin Pharmacol. 2013;69(7):1401-1409.

45. Kwon O, Choe EY, Choi Y, et al. Discovery of dipeptidyl peptidase-4 gene variants and the associations with efficacy of vildagliptin in patients with type 2 diabetes - a pilot study. J Diabetes Metab. 2013;S13:006.

46. Wells RG, Mohandas TK, Hediger MA. Localization of the Na+/ glucose cotransporter gene SGLT2 to human chromosome 16 close to the centromere. Genomics. 1993;17(3):787-789.

47. Yu L, Lv JC, Zhou XJ, Zhu L, Hou P, Zhang H. Abnormal expression and dysfunction of novel SGLT2 mutations identified in familial renal glucosuria patients. Hum Genet. 2011;129(3):335-344.

48. Lee YW. Clinical and genetic analysis in a patient with primary renal glucosuria: Identification of a novel mutation in the SLC5A2 gene. Exp Ther Med. 2013;6(6):1532-1534.

49. Enigk U, Breitfeld J, Schleinitz D, et al. Role of genetic variation in the human sodium-glucose cotransporter 2 gene (SGLT2) in glucose homeostasis. Pharmacogenomics. 2011;12(8):1119-1126.

50. Stenlöf K, Cefalu WT, Kim KA, et al. Efficacy and safety of canagliflozin monotherapy in subjects with type 2 diabetes mellitus inadequately controlled with diet and exercise. Diabetes Obes Metab. 2013;15(4):372-382.

51. Wilding JP, Mathieu C, Vercruysse F, Usiskin K, Deng L, Canovatchel W. Canagliflozin (CANA), a sodium glucose co-transporter 2 inhibitor, improves glycemic control and reduces body weight in subjects with type 2 diabetes (T2D) inadequately controlled with metformin (MET) and sulfonylurea (SU). Poster presented at: American Diabetes Association 72nd Annual Scientific Sessions; June 8-12, 2012; Philadelphia, PA. Abstract 1022P.

52. Forst T, Guthrie R, Goldenberg R, et al. Efficacy and safety of canagliflozin in subjects with type 2 diabetes on metformin and pioglitazone. Poster presented at: 4th World Congress on Controversies to Consensus in Diabetes, Obesity and Hypertension (CODHy); November 8-11, 2012; Barcelona, Spain. Board 64.

53. Cefalu WT, Leiter LA, Yoon KH, et al. Efficacy and safety of canagliflozin versus glimepiride in patients with type 2 diabetes inadequately controlled with metformin (CANTATA-SU): 52 week results from a randomised, double-blind, phase 3 non-inferiority trial. Lancet. 2013;382(9896):941-950. 
54. Gross JL, Schernthaner G, Fu M, et al. Efficacy and safety of canagliflozin, a sodium glucose co-transporter 2 inhibitor, compared with sitagliptin in patients with type 2 diabetes on metformin plus sulfonylurea. Abstract presented at: American Diabetes Association 72nd Annual Scientific Sessions; June 8-12, 2012; Philadelphia, PA. Abstract 50.

55. Lavalle-González FJ, Januszewicz A, Davidson J, et al. Efficacy and safety of canagliflozin compared with placebo and sitagliptin in patients with type 2 diabetes on background metformin monotherapy: a randomised trial. Diabetologia. 2013;56(12):2582-2592.

56. Toubro S, Cefalu WT, Xie J, et al. Canagliflozin reduces body weight mainly through loss of fat mass in subjects with type 2 diabetes. Poster presented at: 4th World Congress on Controversies to Consensus in Diabetes, Obesity and Hypertension (CODHy); November 8-11, 2012; Barcelona, Spain. Board 72.

57. Sinclair A, Bode B, Harris S, et al. Efficacy and safety of canagliflozin compared with placebo in older patients with type 2 diabetes mellitus: a pooled analysis of clinical studies. BMC Endocr Disord. 2014;14:37.

58. Elmore LK, Baggett S, Kyle JA, Skelley JW. A review of the efficacy and safety of canagliflozin in elderly patients with type 2 diabetes. Consult Pharm. 2014;29(5):335-346.

59. Polidori D, Mari A, Ferrannini E. Canagliflozin, a sodium glucose cotransporter 2 inhibitor, improves model-based indices of beta cell function in patients with type 2 diabetes. Diabetologia. 2014;57(5):891-901.
60. Devineni D, Vaccaro N, Polidori D, Rusch S, Wajs E. Effects of hydrochlorothiazide on the pharmacokinetics, pharmacodynamics, and tolerability of canagliflozin, a sodium glucose co-transporter 2 inhibitor, in healthy participants. Clin Ther. 2014;36(5):698-710.

61. Sha S, Polidori D, Heise T, et al. Effect of the sodium glucose cotransporter 2 inhibitor, canagliflozin, on plasma volume in patients with type 2 diabetes mellitus. Diabetes Obes Metab. 2014;16:1087-1095.

62. Nyirjesy P, Sobel JD, Fung A, et al. Genital mycotic infections with canagliflozin, a sodium glucose co-transporter 2 inhibitor, in patients with type 2 diabetes mellitus: a pooled analysis of clinical studies. Curr Med Res Opin. 2014;30(6):1109-1119.

63. Aquilante CL, Wempe MF, Spencer SH, Kosmiski LA, Predhomme JA, Sidhom MS. Influence of CYP2C $8 * 2$ on the pharmacokinetics of pioglitazone in healthy African-American volunteers. Pharmacotherapy. 2013;33(9):1000-1007.

64. Martis S, Peter I, Hulot JS, Kornreich R, Desnick RJ, Scott SA. Multi-ethnic distribution of clinically relevant CYP2C genotypes and haplotypes. Pharmacogenomics J. 2013;13(4):369-377.

65. Grant RW, Hivert M, Pandiscio JC, Florez JC, Nathan DM, Meigs JB The clinical application of genetic testing in type 2 diabetes: a patient and physician survey. Diabetologia. 2009;52(11):2299-2305.
Pharmacogenomics and Personalized Medicine

\section{Publish your work in this journal}

Pharmacogenomics and Personalized Medicine is an international, peer-reviewed, open access journal characterizing the influence of genotype on pharmacology leading to the development of personalized treatment programs and individualized drug selection for improved safety, efficacy and sustainability. This journal is indexed

\section{Dovepress}

on the American Chemical Society's Chemical Abstracts Service (CAS). The manuscript management system is completely online and includes a very quick and fair peer-review system, which is all easy to use. Visit http://www.dovepress.com/testimonials.php to read real quotes from published authors.

Submit your manuscript here: http://www.dovepress.com/pharmacogenomics-and-personalized-medicine-journal 